Rhode Island College

Digital Commons @ RIC

$1-1-2014$

\title{
Hypertension Management among Cambodian-Americans in Rhode Island
}

Rathana Long

Rhode Island College

Follow this and additional works at: https://digitalcommons.ric.edu/etd

Part of the Other Nursing Commons

\section{Recommended Citation}

Long, Rathana, "Hypertension Management among Cambodian-Americans in Rhode Island" (2014). Master's Theses, Dissertations, Graduate Research and Major Papers Overview. 242.

https://digitalcommons.ric.edu/etd/242

This Major Paper is brought to you for free and open access by the Master's Theses, Dissertations, Graduate Research and Major Papers at Digital Commons @ RIC. It has been accepted for inclusion in Master's Theses, Dissertations, Graduate Research and Major Papers Overview by an authorized administrator of Digital Commons @ RIC. For more information, please contact digitalcommons@ric.edu. 


\title{
HYPERTENSION MANAGEMENT AMONG
}

\section{CAMBODIANS}

\section{IN RHODE ISLAND}

\author{
by \\ Rathana Long \\ A Major Paper Submitted in Partial Fulfillment \\ of the Requirements of the Degree of \\ Master of Science in Nursing \\ in \\ The School of Nursing \\ Rhode Island College \\ 2014
}




\begin{abstract}
Hypertension is a major risk factor for heart disease and stroke and the focus of much study in the US. However, there is limited transfer of this knowledge in terms of hypertension management in certain recent immigrant groups such as the Cambodian-Americans. Cambodian-Americans are often included among the Asian/Pacific Islanders and are one of the fasting growing populations in the US. The purpose of this study was to explore how Cambodians in Rhode Island manage hypertension. This study used a survey design with a convenience sample of 30 participants who could read, write, and understand English. It was conducted at a Cambodian temple, after IRB approval, and the student researcher used an IRB approved script and informational letter to recruit participants during a Buddhist ceremony being held at the temple. Results demonstrated that the majority of the participants understood the importance of maintaining a healthy lifestyle such as eating more fruits, cutting down on salt in the diet, regular exercise, taking antihypertensive medicines regularly as prescribed by healthcare providers, and avoiding smoking and drinking. An alarming result, however, was that approximately one quarter (26\%) of those interviewed responded that they would stop taking the antihypertensive medications as soon as their blood pressure returned to normal. The results of this pilot study indicated the need for further education and primary care for Cambodian Americans with high blood pressure to better understand how cultural beliefs impact hypertension management. Recommendations for APRNs are identified and discussed.
\end{abstract}




\section{Acknowledgements}

It is a huge accomplishment that I graduated with a Master of Science degree in Nursing. I did not do it all by myself. It would have been impossible for me to accomplish this without the tremendous support and help from the nursing faculty of Rhode Island College. I would like to thank Dr. Cindy Padula and Dr. Patricia Thomas for working very hard and patiently with me on this project. In addition, I also would like to thank Dr. Margaret Mock and Joan Walsh for always supporting me throughout these past years.

In addition, I would like to acknowledge and thank our great friend Dr. Albert Dahlberg MD, PHD, professor of Medical Science for the department of Molecular Biology, Cell Biology, and Biochemistry of Brown University, for supporting my family in many ways. You and Pam have always been supporting us. Thorn is very lucky to work for a great friend/boss like you for the past twenty years.

I also would like to thank my husband, children, families and friends for their support and always believing in me. 


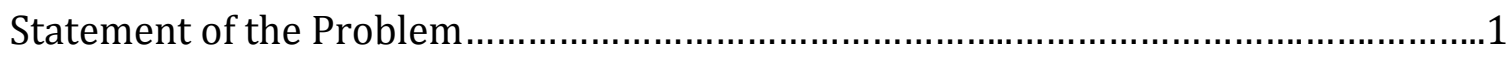

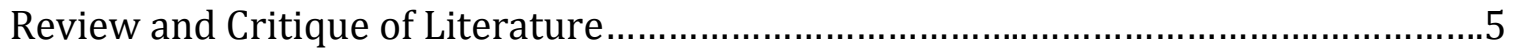

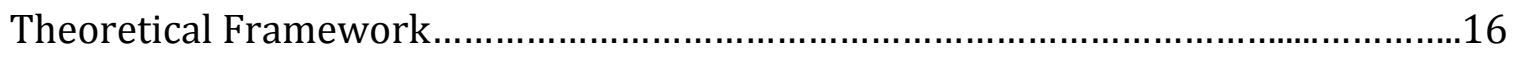

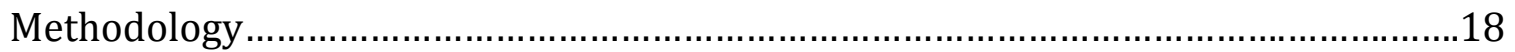

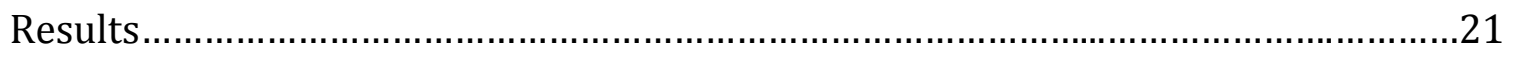

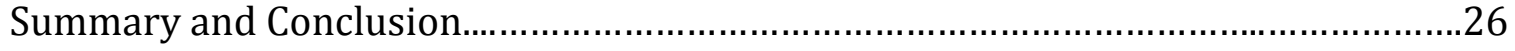

Recommendations and Implications for Advanced Nursing Practice.........................29

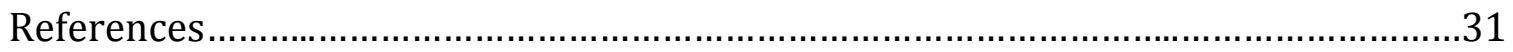

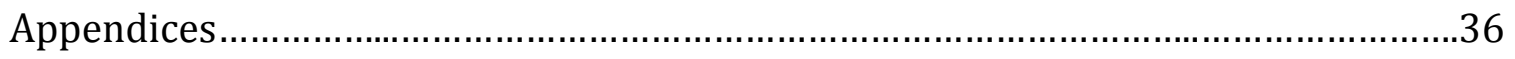


Hypertension Management Among Cambodian-Americans In Rhode Island

\section{Statement of the Problem}

Hypertension (HTN) or high blood pressure (HBP) is a common condition in the United States (US). It is estimated that one in three adults have HTN (National, Heart, Lung, and Blood Institute [NIH], 2014). It is a major cause of morbidity and mortality and costs about $\$ 131$ billion annually in health care expenditures in the US (NIH, 2014). Hypertension is a major leading risk factor for heart disease and stroke. The National Health and Nutrition Examination Survey (NHANES) was implemented to study the awareness and pharmacologic treatment of uncontrolled HTN among US adults aged greater than 18 years between the years 2003-2010. Gillespie and Hurvitz (2013) found that the overall prevalence of HTN among adults aged $>18$ years was $30.4 \%$, or roughly estimated at 66.9 million people. Among those with HTN, an estimated 35.8 million (53.5\%) did not have their hypertension under-control (Gillespie \& Hurvitz, 2013).

Hypertension can affect anyone, with different ethnic subgroups impacted differently. For example, African Americans are commonly impacted more than Caucasian or Hispanic American adults. African Americans tend to get HTN earlier in life, often have more severe HTN, are less likely than Caucasians to achieve target control levels with HTN treatment, even though they are more likely to be aware that they have HTN and to get treatment. Therefore, African Americans have higher rates of early death from HTN-related problems than Caucasians, such as coronary heart disease, stroke, and kidney failure (NIH, 2014). 
There are approximately 17.5 million Asian/Pacific Island Americans (APIASs) in the US. Asian/Pacific Island Americans are the fastest growing population in the US by percentage and they are considered to be decedents of the original peoples of the Far East, Southeast Asia, or the Indian subcontinent (Watson, Karnchanasorn, \& Gossain, 2009). There are approximately 23.8\% Chinese, 18.3\% Filipino, 16.2\% South Asian, 10.9\% Vietnamese, 10.5\% Korean, and 7.8\% Japanese among APIAs in the US. Hypertension increases cardiovascular risk to a great extent in this population (Watson et al, 2009). Heart disease related to HTN is the number two leading cause of death (CDC, 2011). The percentage of APIAs who are aware, treated, and controlled are very small (Watson, et al, 2009). The World Health Organization has also found that the risk of developing type 2 diabetes and heart disease increases at a lower body mass index (BMI) cutoff in Asians (BMI > 23) compared to non-Asians (BMI >25) (Center for Southeast Asian, 2013). This further contributes to an overall underestimation of the relative risk for chronic illnesses among Asian communities and individuals, which explains the alarmingly high rates of HTN, coronary vascular disease (CVD), and obesity (Center for Southeast Asian, 2013).

Recently, in 2009, President Obama signed an executive order calling for strategies to improve the health of Asian Americans and to seek data on the health disparities in Asian American subgroups. Data on Asian Americans subgroups are scarce and many health disparities remain unknown. Since Asian Americans are the fastest growing racial/ethnic group in the US and they represent many different groups, several major federal surveys such as the American Community Survey, the 
National Health Interview Survey, and the Behavioral Risk Factor Surveillance Survey recently started to classify Asian Americans into seven subgroups: Asian Indian; Chinese; Filipino; Korean; Japanese; Vietnamese; and other Asian (Palaniappan et al., 2010).

Cambodians are included in the subgroup 'other Asians', perhaps because until more recently the Cambodian American population was relatively small. Cambodia is a country in South East Asia, less than half the size of California and slightly smaller than the state of Oklahoma. It is bordered by Thailand, Laos, Vietnam, and the Gulf of Thailand (Cambodia, 2004). Historically, most of the few Cambodians in the US were children of upper income families or were those with governmentfunded scholarships sent abroad to attend school prior to 1975. In 1979, a large wave of Cambodians began to immigrate to the US as refugees after the Khmer Rouge was overthrown. In order to encourage rapid assimilation into the American culture and to spread the economic impact, the US government settled these refugees in various towns and cities throughout the country. However, once established enough to be able to communicate and travel, many Cambodians began migrating within the US to certain locations where the climate was more like home, where they knew friends and relatives had been sent, or where there were rumored to be familiar jobs or higher government benefits. Consequently, large numbers of Cambodians settled in cities such as Long Beach, Fresno, and Stockton in California, Providence, Rhode Island (RI), Cleveland, Ohio, as well as Lynn and Lowell in Massachusetts, and in the Pacific Northwest, Seattle and Portland. The 2010 US Census counted 276,667 persons of Cambodian descent in the US, up from 206,052 
in 2000. Of those, 231,616 (84\%) are Cambodian alone and 45,051 are part Cambodian (U.S Census, 2010).

Cambodians are included under the 'other Asian' subgroup, within the APIAs, but more specifically Cambodians is Southeast Asians (SEA) that includes Burmese, Cambodian, Filipino, Laotian, Vietnamese, Hmong, and Thai. According to Southeast Asian data and trends analysis, there are about 37,000 Asians living in RI (3.1\% of the state's total population), of which about $35.7 \%(13,209)$ are Cambodians (Center for Southeast Asians, 2013). Cambodians are included in the SEA ethnic groups whose health data (local, state wide, and national) are generally pooled, not listed separately. This provides only aggregate information about the general Asian and APIA community.

There are some reports with data specific to Cambodians. The National Heart, Lung and Blood Institute ranks CVD and diabetes as the top two health concerns in the Lowell Cambodian community of MA (Center for Southeast Asian, 2013). According to the RI Department of Health (2010), heart disease is the second leading cause of death among APIAs in RI. Locally in RI, over one-third of Asian patients seen at the Free Clinic from March 2013 to August 2013 presented with HTN and hyperlipidemia. These data demonstrate that hypertension is a health problem among Cambodians. The primary purpose of my study here (using a small population sample) is to explore how Cambodians in Rhode Island manage their hypertension. 


\section{Review and Critique of the Literature}

The existing relevant literature was electronically searched thru CINAHL, OVID, PUBMED, MEDLINE, and UP TODATE with the following key words: Cambodians; hypertension; high blood pressure; health; culture; Cambodians health; Cambodians with hypertension; Asians with high blood pressure; Asian Americans; minority health; Southeast Asians; Asian Pacific Islander and Rhode Island. The titles and abstracts were reviewed to identify if they were suitable articles and then the full text versions were read to determine the relevance of the articles to the focus of this research study.

\section{Definition of Hypertension}

What is blood pressure? Blood pressure is the force of blood on the walls of the blood vessels as blood flows through them. Blood pressure readings include two numbers, systolic and diastolic, and are measured in millimeters of mercury (mmHg). Systolic pressure is the force on the blood vessel walls when the heart beats and pumps blood out of the heart, which also is the top number. Diastolic pressure is the force that occurs when the heart relaxes in between beats, which is the bottom number (CDC, 2014). Hypertension or HBP has been defined as "sustained elevation of systolic blood pressure (SBP) of $140 \mathrm{mmHg}$ or above, or of diastolic blood pressure (DBP) of $90 \mathrm{mmHg}$ or above, at least three times on two different occasions and includes individuals currently taking antihypertensive pharmacologic agents." (Barkley \& Javier, 2008, pp. 95).

Table 1 outlines how the National Heart, Lung, and Blood Institute (NIH) standardized the definition of HTN. 
Table 1

Stages of Hypertension

\begin{tabular}{|c|c|c|}
\hline Stages of Blood Pressure & Systolic Value (mmHg) & Diastolic Value (mmHg) \\
\hline Normal & Less than 120 & Less than 80 \\
\hline Prehypertension & $120-139$ & $90-99$ \\
\hline Stage I Hypertension & $140-159$ & 100 or higher \\
\hline Stage II Hypertension & 160 or higher & \\
\hline
\end{tabular}

Prehypertension is not a disease, rather it is a designation chosen to identify individuals at high risk of developing HTN. Therefore, patients should be alerted to this risk and encouraged to intervene and prevent or delay the disease from developing. Individuals with prehypertension are not candidates for drug therapy based on their level of BP and should be strongly advised to practice lifestyle modification to reduce their risk of developing HTN in the future (The Seventh Report of the National Joint Committee [JNC 7], 2004). The goal for individuals with prehypertension without compelling indications is to lower BP to normal levels with lifestyle changes, and to prevent the progressive rise in BP with the recommended lifestyle modifications (Martin, 2008).

In the JNC 7 guidelines, stage I hypertension is defined as a systolic SBP of 140 $\mathrm{mmHg}$ to $159 \mathrm{mmHg}$ or a diastolic blood pressure (DBP) of $90 \mathrm{mmHg}$ to $99 \mathrm{mmHg}$ (Martin, 2008). Stage II hypertension is when SBP is greater than or equal to 160 $\mathrm{mmHg}$ or DBP is greater than or equal to $100 \mathrm{mmHg}$ (Martin, 2008). The systolic and diastolic numbers may not fall into the same BP category as in stage one and/or 
stage two. If that is the case, the more severe category is the one that is diagnosed. For example, if the systolic number is 160 and the diastolic number is 80 , this is an indication of stage II HTN. If the systolic number is 120 and the diastolic number is 95, the reading is an indication of stage I HTN $(\mathrm{NIH}, 2012)$. It is very important to determine the stages of HBP because the stages of HBP determine the kinds of treatments that are needed to adequately get the BP under-control (NIH, 2012).

\section{Hypertension Treatment}

Hypertension is a common major risk factor for cardiovascular disease and stroke and about $50 \%$ of those with HTN are not adequately controlled (Bauchner, Fontanarosa, \& Golub, 2013). The majority of people with HTN are treated effectively with both lifestyle interventions and relatively inexpensive medications by primary care physicians (Bauchner et al., 2013). The Eighth Joint National Committee (JNC 8, 2014) revised the guideline for management of HBP in adults with the main objective to attain and maintain goal BP. If goal BP is not reached within a month of treatment, the recommendation is that the dose of the initial drug be increased or a second drug be added from one of the following classes: thiazide-type diuretic; calcium channel blocker (CCB); angiotensin-converting enzyme inhibitor (ACEI); or angiotensin receptor blocker (ARB). The Eighth Joint National Committee also recommended that the clinicians should continue to assess BP and adjust the treatment regimen until goal BP is reached. If goal BP cannot be reached with two drugs, the guideline recommends adding and titrating a third drug but not to use an ACEI and ARB together in the same patient. It is also recommended to refer patients to a hypertension specialist if the goal BP cannot be attained (James et al., 2014).

\section{Risk Factors}

The risk factors for HBP include age, race and certain ethnicities, overweight or obesity, gender, unhealthy lifestyle habits, and family history (NIH, 2012). Blood 
pressure tends to rise with age, and about $65 \%$ of Americans aged 60 or older have HTN (NIH, 2012). Gender plays a major role in HBP: men are more likely to have HBP than women before age 45 . However, at age 65 , the condition is more likely to affect the women than men. In addition, men who are younger than 55, are more likely to have uncontrolled HTN than women. At age 65, women are more likely to have uncontrolled HBP (NIH). Unhealthy lifestyle habits such as eating too much sodium, drinking too much alcohol, not getting enough potassium in diet, lack of physical activity, overweight or obesity, and smoking are the modifiable risk factors for HBP. Other risk factors include family history, long-lasting stress, and prehypertension (NIH).

Hypertension can affect anyone but it is more common in African American adults than in Caucasian or Hispanic American adults. In relation to these groups, African Americans tend to get HTN earlier in life, tend to have more severe HBP, and are more likely to be aware that they have HTN and get treatment. However, they are less likely to achieve the target control levels with HTN treatment (NIH, 2012). African American adults have high rates of early death from HBP related problems such as coronary heart disease (CAD), stroke, and kidney failure (NIH). Data specific to Asians, including Cambodians in particular, is limited.

A selected review of cardiovascular disease and risk factors in Asia by Ueshima et al. (2008) reported that international study of macro and micro nutrients and blood pressure revealed that blood pressure levels and prevalence of hypertension in the northern part of China were higher than those in the southern part of China. According to this review, the difference in BP between the north and south populations is partly explained by the difference in salt consumption (Ueshima et al, 2008). The total number with HTN in China and India is expected to increase to more than 500 million by 2025, but the 
awareness of HTN in Asia is less than $50 \%$ of that in China and India, and these rates are far lower than in Western countries. Also, the treatment rate is lower in Asia, especially in low-income countries (Ueshima et al, 2008).

Heart disease that is related to HBP is the number two killer for Asian Americans in RI, including Cambodians. Hypertension is also a risk factor for stroke, and the number three killer for Asian Americans in RI (Minority Health Facts, 2011). The Health Disparities in Southeast Asian and African Refugee Communities found that CambodianAmericans have very high rates of heart disease, stroke, and HTN (Pierce, 2010).

\section{Epidemiology}

Hypertension is the number one modifiable risk factor for stroke and it is one of the most important modifiable risks for CVD (Wu, Tai, Heng, Tan, Low, \& Lee, 2009). In addition to stroke, HTN also contributes to heart attacks, heart failure, kidney failure, and atherosclerosis. Hypertension affected $26.4 \%$ of the world's adult population (972 million) in 2000, and the rates are expected to increase to $29.2 \%$ (1.56 billion) by 2025 . In both developing and developed countries, HBP has been identified as the leading risk for mortality (Wu et al, 2009).

In the US, one in three adults have HTN, and nearly one-third of these people are not aware that they have it. It is often called the "silent killer" because there are no symptoms associated with HTN (CDC, 2014). Approximately 65\% of Americans aged 60 or older have HBP, and approximately 67 million people require medial care to work to keep their BP in check each day. Unfortunately, more than half of people with HTN do not have their condition under control (CDC, 2014).

A California Health Interview Survey (CHIS) studied the health status of older Asian Americans including Chinese, Japanese, Korean, Vietnamese, and Filipino peoples in California (sample size of 51,048 participants). The authors found that the most common chronic disease was HTN, with $60.2 \%$ of the population being impacted (Kim, Chiriboga, Jang, Lee, Huang, \& Parmelee, 2010). In terms of comorbidity, 69.8\% of older Asians 
had at least one chronic disease and $26 \%$ had two or more chronic diseases. This study extensively compared health status of different subcategories of older Asian Americans but failed to include Cambodians. Results of this study were striking in identifying that there were differences in many demographic, immigration-related, and physical and mental health characteristics between the subcategories. The data suggested that combining the diverse subcategories of Asians might provide misleading information about health status, which in turn could lead to problems with the identification of needs for health care (Kim et al, 2010).

Work at the Department of Health Promotion and Gerontology, University of Texas Medical Branch, Galveston Texas Consortium of Geriatric Education Center, focused on the Health and Health Care of Southeast Asian American Elders: Vietnamese; Cambodian; Hmong; and Laotian. This descriptive module reported that life expectancy in Cambodia is approximately 47 years for men and 49 years for women, with no life expectancy data for Cambodians in the U.S. Cambodians are also at very high risk for mental health problems and many suffer from post-traumatic stress disorder and depression that is exacerbated by financial stress. In addition, Cambodians also have a high rate of HTN, diabetes, heart disease, stroke, and seizures that are usually accompanied by a variety of somatic complaints such as headaches, stomachaches, dizziness, and fatigue (Yee, nd). This project did not address strategies used for prevention or management.

\section{Hypertension Management in Asian Americans}

Watson, Karnchansorn, and Gossain (2009) studied HTN in Asian/Pacific Island Americans (APIAs) and examined the prevalence of HTN, genetics and HTN in APIAs, awareness of HTN, treatment, and response to drug treatment, effectiveness of tea drinking on HTN, and side effects of hypertensive medications. The authors validated that HTN is a common problem among APIAs and a strong risk factor for coronary heart disease and stroke in APIAs, as it is in Caucasians. A Northern California study found 
that the prevalence of HTN was $22 \%$ in Chinese, $26.9 \%$ in Filipino, and $21.7 \%$ in Japanese Americans. These numbers are similar to those noted in white Americans (Barnes, Adams, \& Powell-Griner, 2008). The 2004 - 2006 National Health Interview Survey (NHIS) conducted by CDC found that the Filipino adults (27\%) and Japanese adults $(25 \%)$ were more likely than Chinese $(17 \%)$ or Korean adults $(17 \%)$ to have ever been told they have HTN. In addition, overall, Asian adults were less likely (22\%) and African American adults (36\%), American Indian or Alaskan native adults (32\%) were more likely to have ever been told they have HTN, compared with white $(25 \%)$ or Hispanic adults (24\%) (Barnes et al, 2008). The study concluded that there were many gene mutations associated with HTN that were common in Asian populations but the significance of polymorphisms in the pathogenesis of HTN in APIAs was unclear. The study also found that the awareness, treatment, and control of HTN in APIAs were low and much more effort was needed to improve the statistics. There were conflicting results on the tea drinking and some differences on the response to antihypertensive medications between the Caucasians and APIAs. This study pointed out that there was a need for more education of APIAs regarding the importance of HTN and its' control, and there was also a need for more effective treatment of HTN by the health care providers who care for this population.

The Lowell Community Health Center (LCHC) developed a long-term "whole community" best practice model to address health disparities in the Cambodian refugee and immigrant community of Lowell, Massachusetts in 2010. The Lowell Community Health Center is a federally qualified health center, recognized for its cultural competence and use of Culturally and Linguistically Appropriate Service standards. Twenty two percent of 32,000 patients at the LCHC were Cambodian in 2008 (GriggSaito et al, 2010). This article mentioned many social and health disparities among Cambodians such as poverty, limited education, cardiovascular disease including HBP, diabetes, mental health, including post-traumatic stress disorder and depression, which 
influence their ability to practice prevention and obtain treatment (Grigg-Saito \& et, 2010). The whole community-approach model developed many programs that address physical, psycho-social and spiritual needs at its center for promoting change and recognition of generational differences and the critical role of bilingual, bicultural community health workers. This model focuses on individual and institutional barriers to care such as language, health beliefs, limited literacy, trust levels, and understanding of US health care. The services in this model are: (1) the outreach, which includes a culturally adapted curriculum, and local cable advertisements; (2) the Refugee and Immigrant Safety and Empowerment Network, which focuses on supporting Cambodian domestic violence victims, working within a network of service providers; (3) the Language Access System Improvement Team, which works to improve access to interpreter services for patients through in-house cultural competency training, signage, and patient input (Grigg-saito et al, 2010). The results of these programs showed that better health outcomes were made possible by building trusting relationships. Results demonstrated that all 50 Cambodian patients showed improvements over baseline: $62 \%$ in BP, blood glucose, and dietary habits for disease management; $30 \%$ in medication compliance; and $11 \%$ in ability to communicate proficiently with health care providers (Grigg-saito \& et, 2010). These developmental programs are very helpful to the Cambodian community and these programs could possibly emerge in other communities such as in RI to help guide Cambodian residents in the management of their HTN.

Ursua et al. (2008) conducted a cross-sectional analysis of survey data of 566 Filipinos diagnosed with HTN. The objectives of the study were to identify 1) the rates of HTN awareness, treatment, and control; and 2) factors associated with awareness, treatment, and control. Survey data were collected from 2006 to 2010. The authors found that the awareness, treatment, and control rates among the hypertensive Filipinos were suboptimal: $72.1 \%$ were aware of their hypertensive status; $56.5 \%$ were on medication; and only $21.7 \%$ had controlled BP (Ursua et al, 2008). The majority of hypertensive 
individuals were aware of their HTN status, but only a small percentage of them were treated and had achieved BP control. In addition, a large percentage of hypertensive individuals had other CVD risk factors: $60.4 \%(n=341)$ were overweight or obese with BMI $>25 ; 12.0 \%(n=68)$ had at-risk glucose measurements; and 12.8\% $(n=72)$ had cholesterol level > 240 (Ursua et al, 2008). The researchers concluded that hypertensive Filipinos exhibited poor HTN management, warranting increased efforts to improve awareness, treatment, and control. Culturally tailored public health strategies must be prioritized to reduce CVD risk factors among at-risk minority populations. The study also found that older age, having lived in the US for 15 years or more, and not smoking were directly associated with treatment (Ursue et al, 2008). While this study examined Filipinos, results are applicable to Cambodians, the focus of this project.

Bitton and others (2010) conducted a retrospective study of the Behavioral Risk Factor Surveillance System surveys to compare self-reporting of health risk factors, chronic diseases, and access to care among 2609 Pacific Islanders, (PIs) 17,892 Asians, and 894,289 whites over age 18. Results demonstrated that PIs were more likely than Asian Americans to report an elevated body-mass index, current smoking, high alcohol intake, and adequate physical activity. In addition, these subjects also reported higher adjusted rates of HTN, diabetes, asthma, and arthritis. There were no differences in measures of access to care between the PIs and Asian Americans. In comparison to white subjects, PIs were more likely to report a diagnosis of diabetes but less likely to report arthritis. No significant differences in other outcomes measures were detected. The authors concluded that health surveys and policies should distinguish between PIs and Asian Americans given the significantly higher rates of health risks and chronic diseases among PI (Bitton et al, 2010).

Overall, there are some limited studies of HTN in Asian Americans in general, but none that specifically focus on Cambodian-Americans. There is a need for education tailored to the needs of APIAs regarding HTN and its control (Watson et al, 2009), as 
well as a need for more effective treatment of HTN by the health care providers who treat this population. As a consequence of these needs, I undertook the following study. Although limited in sample size, the project was designed to determine how Cambodians in Rhode Island manage hypertension.

\section{Theoretical Framework}

Leininger's Cultural Care Diversity and Universality Theory (2007) will guide the development of this project. Leininger recognized the importance of the concept of caring in nursing early in her career as a nurse. Frequent statements of appreciation from patients for care received prompted Leininger to focus on care as a central component of nursing. She identified a lack of cultural care knowledge as the missing link in nursings' 
understanding of how many variations are required in patient care to support compliance, healing, and wellness.

The purpose of Leininger's theory is to generate knowledge related to the nursing care of people who value their cultural heritage and lifeway. The major concepts of the model are culture, culture care, and culture care differences (diversities) and similarities (universals) pertaining to transcultural human care (McEwen \& Wills, 2011).

Leininger's other major concepts are care and caring with an emic approach such as language expression, perception, belief, and practice of individuals or groups of a particular culture in regard to certain phenomena, and an etic approach which includes universal language expression, belief, and practices in regard to certain phenomena that pertain to several cultures or groups, the lay system of health care, the professional system of health care, and culturally congruent nursing care (Leininger, 2007). The goal of Leininger's theory is to provide culturally congruent nursing care to persons of diverse cultures. A central principle of the theory is that it is important for nurses to understand the individual's view of illness; and, in addition, focus on recognizing and understanding cultural similarities and differences and using this information to positively influence nursing care and health (Leininger, 2007).

Asian peoples represent a large, multiethnic group with different cultural and religious beliefs and practices. The Cambodians are one of the subgroup of Asians that often are not included in studies. Therefore, it is essential that when healthcare providers attempt to provide appropriate interventions for patients with HTN that they understand both the concerns of the individual and the beliefs and expectations of the culture of their community. Researchers have used Leininger's theory widely. Catolico (2013) used Leininger's theory for her study on Seeking Life Balance: The Perceptions of Health of Cambodian Women in Resettlement. According to Catolico (2013), the theoretical model of seeking life balance aligns well with the Leininger's theory of culture care diversity and universality (Catolico, 2013). 


\section{Methodology}

\section{Purpose}

The primary purpose of this study was to explore how a sample of Cambodians in RI manages hypertension.

\section{Design}

This study used a qualitative descriptive survey design.

\section{Sample and Site}

The sample of the study included Cambodian people aged greater than 18 years. Both males and females were eligible to be included, and the target sample size was 30 participants maximum. The participants were required to be able to read, write, and understand English. This study took place at the Cambodia temple, Wat Dhamagosnaram, 2870 Plainfield Pike, Cranston, RI 02921.

\section{Procedures}


The student researcher obtained Rhode Island College Institutional Review Board (RICIRB) approval for the study as well as written permission from the chief monk of the temple (Appendix A).

The student researcher attended regularly scheduled Buddhist weekend ceremonies from 10am-noon. The monk introduced the student researcher and asked participants if they would be interested in learning more about a research study that they might be eligible to participate in. The student researcher then introduced herself to those who were interested and briefly explained the purpose and the procedures of the research study, using an IRB approved script (Appendix B).

Those people who identified that they had high blood pressure and were interested in participating contacted the student researcher by phone and a meeting was arranged. The participants were given the IRB approved information consent letter (Appendix B) to sign along with a copy of the survey questions (Appendix C). Each participant was told to answer the questions at his/her own pace, and was reminded that he/she was free to not answer any questions if he/she so wished. No identifiers were present on the survey.

After the surveys were completed, the student researcher provided blood pressure measurement for all those who wished to have it done, along with the IRB approved debriefing statement (Appendix C). If blood pressure was determined to be high, he student investigator, who is a skilled professional nurse, repeated the reading following American Heart Association (AHA) procedures and guidelines and instructed participants appropriately. Completed surveys were stored in a locked box at the student researcher's home, to which only the student researcher had access.

\section{Measurement}


This study used a survey developed and reported by Eugene and Broune (2013). The survey had three distinct components: 1) social-demographic characteristics of the sample, 2) knowledge of high blood pressure and 3) self-management practice. For purposes of this study, only the socio-demographic and self-management questions were employed. In addition, two open ended questions also identified by Eugene and Broune were used: 'How long have you been diagnosed with high blood pressure?' and 'How many medications are you taking for high blood pressure?' (Appendix D).

The strength of using this survey was that it had been used in samples of other than Caucasian peoples, including Jamaicans. A limitation was that though used in a study conducted by Eugene and Broune, psychometric data specific to the measure were not reported. The survey was pilot tested with a few Cambodians with hypertension prior to use in the study.

\section{Data Analysis}

Data were entered into an excel file, and descriptive statistics and percentages were calculated. 


\section{Results}

A total of 30 subjects participated in the study; 15 males and 15 females.

Demographic characteristics of the study sample are illustrated in Table 1, including age categories, level of education, and marital status.

Table 1

Demographic Characteristics of Study Participants $(N=30)$

\begin{tabular}{|l|r|r|}
\hline & Number & Percentage \\
\hline Age & & \\
\hline $18-24$ years old & 0 & 0.00 \\
\hline $25-34$ years old & 0 & 0.00 \\
\hline $35-44$ years old & 3 & 10.00 \\
\hline $45-54$ years old & 7 & 43.33 \\
\hline $55-64$ years old & 7 & 23.33 \\
\hline $65+$ years old & & 23.33 \\
\hline & & \\
\hline Level of Education & 16 & 53.33 \\
\hline High School graduate & 11 & 36.67 \\
\hline 2 years Associate degree & 3 & 10.00 \\
\hline 4 years Bachelor degree & 0 & 0.00 \\
\hline Master degree & 0 & 0.00 \\
\hline PhD & & \\
\hline
\end{tabular}




\begin{tabular}{|l|r|r|} 
Marital status & & \\
\hline Single & 3 & 10.00 \\
\hline Married & 22 & 73.33 \\
\hline Common-Law & 0 & 0.00 \\
\hline Widowed & 5 & 16.67 \\
\hline
\end{tabular}

There were no participants aged 18 to 34 , and only $10 \%(n=3)$ of participants were between 35 to 44 years old. The majority of the participants were between age 45 and 54 years old (43.33\%), and another $23 \%(n=7)$ were greater than 65 years of age. Educational level ranged from high school graduate to the bachelor's degree: more than half were high school graduates $(n=16 ; 53.33 \%), 36.67 \%(n=$ 11) held an associate degree, and $10 \%(n=3)$ had completed a bachelor's degree. The majority of the sample was married $(73.33 \% ; n=22)$ and there were no common-law marriages.

The number of years that participants had been diagnosed with HTN and number of antihypertensive medications that participants took are illustrated in Table 2. Eleven people $(36.66 \%)(n=11)$ had been diagnosed with HTN for one year. Another $46.6 \%$ of subjects had been diagnosed between one and five years ago and the remainder $(n=5 ; 16.32 \%)$ had been diagnosed for more than five years. The majority of these participants were taking only one antihypertensive medication (n $=22 ; 73.33 \%)$ and only one was taking three antihypertensive medications (3.33\%). 
Table 2

Participants' Years with HTN Diagnosis and Number of HTN Medications

\begin{tabular}{|c|c|c|}
\hline & Number & Percentage \\
\hline Participants & 30 & \\
\hline \multicolumn{3}{|l|}{ Yrs of Dx } \\
\hline 1 & 11 & 36.66 \\
\hline 2 & 5 & 16.66 \\
\hline 3 & 1 & 3.33 \\
\hline 4 & 3 & 10 \\
\hline 5 & 5 & 16.66 \\
\hline 6 & 0 & 0 \\
\hline 7 & 1 & 3.33 \\
\hline 8 & 0 & 0 \\
\hline 9 & 0 & 0 \\
\hline 10 & 1 & 3.33 \\
\hline 11 & 1 & 3.33 \\
\hline 12 & 0 & 0 \\
\hline 13 & 0 & 0 \\
\hline 14 & 0 & 0 \\
\hline 15 & 2 & 6.66 \\
\hline \multicolumn{3}{|l|}{ \# HTN Meds } \\
\hline 1 & 22 & 73.33 \\
\hline 2 & 4 & 13.33 \\
\hline 3 & 1 & 3.33 \\
\hline 4 & 3 & 10 \\
\hline
\end{tabular}




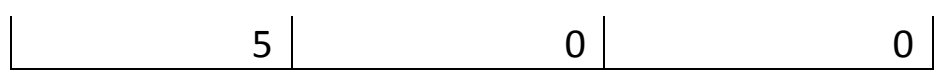

The responses to the Self-Care Management questionnaire are illustrated in Table 3.

The actual questions are illustrated below.

1. I will eat more fruits and vegetables

2. I will put less salt in my food

3. I make every attempt to avoid smoking cigarettes

4. I make every attempt to avoid drinking alcohol

5. I take my medication daily as prescribed by the doctor

6. As a person with high blood pressure, I will exercise regularly

7. As soon as the blood pressure is low, I can stop taking the medication(s)

8. It is $\mathrm{OK}$ for the persons with high blood pressure to take Khmer herbal medications to lower their blood pressure.

Table 3

Responses to Self-care Management Questions ( $\mathrm{N}=30$ )

\begin{tabular}{|l|l|l|l|l|l|}
\hline Questions & $\begin{array}{l}\text { Strongly } \\
\text { Disagree } \\
(\mathrm{n} ; \%)\end{array}$ & $\begin{array}{l}\text { Disagree } \\
(\mathrm{n} ; \%)\end{array}$ & $\begin{array}{l}\text { Neutral } \\
(\mathrm{n} ; \%)\end{array}$ & $\begin{array}{l}\text { Agree } \\
(\mathrm{n} ; \%)\end{array}$ & $\begin{array}{l}\text { Strongly } \\
\text { Agree } \\
(\mathrm{n} ; \%)\end{array}$ \\
\hline 1 & $0(0 \%)$ & $1(3.33 \%)$ & $3(10 \%)$ & $15(50 \%)$ & $11(36.66 \%)$ \\
\hline 2 & $1(3.33 \%)$ & $0(0 \%)$ & $8(26.66 \%)$ & $13(43.33 \%)$ & $8(26.66 \%)$ \\
\hline 3 & $0(0 \%)$ & $0(0 \%)$ & $2(6.66 \%)$ & $9(30 \%)$ & $19(63.33 \%)$ \\
\hline 4 & $0(0 \%)$ & $3(10 \%)$ & $4(13.33 \%)$ & $14(46.66 \%)$ & $9(30 \%)$ \\
\hline 5 & $1(3.33 \%)$ & $2(6.66 \%)$ & $4(13.33 \%)$ & $6(20 \%)$ & $16(53.33 \%)$ \\
\hline 6 & $0(0 \%)$ & $5(16.66 \%)$ & $6(20 \%)$ & $9(30 \%)$ & $10(33.33 \%)$ \\
\hline 7 & $12(40 \%)$ & $6(20 \%)$ & $4(13.33 \%)$ & $7(23.33 \%)$ & $1(3.33 \%)$ \\
\hline 8 & 10 & $12(40 \%)$ & $4(13.33 \%)$ & $1(3.33 \%)$ & $3(10 \%)$ \\
\hline
\end{tabular}


\begin{tabular}{|l|l|l|l|l|l|}
\hline & $(33.33 \%)$ & & & & \\
\hline
\end{tabular}

For ease in interpreting responses, responses were collapsed as illustrated in

Table 4 below. Strongly disagree and disagree categories were collapsed to

'Disagree', and strongly agree and agree were collapsed into 'Agree'.

Table 4

Summary of responses to self-care management Questions $(\mathrm{N}=30)$

\begin{tabular}{|c|c|c|c|}
\hline Questions & Disagree $(\mathrm{n} ; \%)$ & Neutral (n;\%) & Agree (n;\%) \\
\hline 1 & $1 \quad(3.33 \%)$ & $3(10 \%)$ & $26(86.66 \%)$ \\
\hline 2 & $1 \quad(3.33 \%)$ & $8(26.66 \%)$ & $21(69.99 \%)$ \\
\hline 3 & $0 \quad(0 \%)$ & $2(6.66 \%)$ & $28(93.33 \%)$ \\
\hline 4 & $3 \quad(10 \%)$ & $4(13.33 \%)$ & $23(76.66 \%)$ \\
\hline 5 & $3 \quad(10 \%)$ & $4(13.33 \%)$ & $22(73.33 \%)$ \\
\hline 6 & $5 \quad(16.66 \%)$ & $6(20 \%)$ & $19(63.33 \%)$ \\
\hline 7 & $18(60 \%)$ & $4(13.33 \%)$ & $8 \quad(26.66 \%)$ \\
\hline 8 & 22 (73.33\%) & $4(13.33 \%)$ & $4 \quad(13.33 \%)$ \\
\hline
\end{tabular}

The majority of the participants was aware and attempted to avoid smoking cigarettes $(n=28 ; 93.33 \%)$, followed by eating more fruits and vegetables $(n=26$; 86.66\%), avoiding alcohol ( $\mathrm{n}=23 ; 76.66 \%)$, taking antihypertensive medication(s) daily as prescribed by doctor or health care provider $(n=22 ; 73.33 \%)$, and exercising regularly $(n=19 ; 63.33 \%)$. Approximately $26.66 \%(n=8)$ agreed that they could stop taking antihypertensive medication(s) as soon as their blood 
pressure was s low and $13.33 \%(\mathrm{n}=4)$ agreed that it was okay to take Khmer herbal medication(s) to lower their blood pressure.

\section{Summary and Conclusions}

Hypertension (HTN) or high blood pressure (HBP) is a common condition in the US. It is estimated that one in three adults have HTN (National, Heart, Lung, and Blood Institute [NIH], 2014), which is a major cause of morbidity and mortality. Hypertension costs about $\$ 131$ billion annually in health care expenditures in the US (NIH, 2014) and is a major leading risk factor for heart disease and stroke. The National Health and Nutrition Examination Survey (NHANES) was implemented to study the awareness and pharmacologic treatment of uncontrolled HTN among US adults aged greater than 18 years between the years 2003-2010. Gillespie and Hurvitz (2013) found that the overall prevalence of HTN among US adults aged $>18$ years was $30.4 \%$, roughly estimated at 66.9 million people. Among those with HTN, an estimated 35.8 million (53.5\%) did not have their hypertension under-control. 
Cambodians are one of the SEA ethnic groups for which health data that is gathered locally, state wide, and nationally data sources are generally not disaggregated. Instead, such data sources tend to contain only aggregate information on the general Asian and APIA community in general. The National Heart, Lung and Blood Institute ranks CVD and diabetes as the top two health concerns in the Lowell Cambodian community (Center for Southeast Asian, 2013). According to the RI Department of Health (2010), heart disease is the second leading cause of death among APIAs in RI. Locally in RI, over one-third of Asian patients seen at the Free Clinic from March 2013 to August 2013 presented with HTN and hyperlipidemia.

Heart disease that is related to HBP is the number two killer for Asian Americans in RI, including Cambodians. Hypertension is also a risk factor for stroke, and the number three killer for Asian Americans in RI (Minority Health Facts, 2011). The Health Disparities in Southeast Asian and African Refugee Communities found that Cambodian-Americans have very high rates of heart disease, stroke, and HTN (Pierce, 2010). The primary purpose of this study was to explore how a small sample of Cambodians in Rhode Island managed hypertension.

Based on the data derived from this pilot study, the majority of participants agreed that they should eat more fruits, cut down on salt intake, avoid smoking cigarettes, avoid drinking, take their antihypertensive medication(s) daily as prescribed by their doctor or health care provider, and exercise regularly. In contrast, however, an alarming concern was that eight participants (26.66\%) agreed that as soon as their blood pressure was low, that they can stop taking their 
antihypertensive medication(s). Four participants also agreed that it was all right to take Khmer herbal medications to lower their blood pressure (13.33\%).

This descriptive study had a small sample size. A study with a larger sample of participants is indicated. The requirement was that participants needed to be able to read, understand and write English. It is likely that the older adults are the most vulnerable and potentially most impacted by this requirement. The study was conducted at only one temple and subsequent follow-up studies at other sites are indicated.

In conclusion, further education related to hypertensive management among Cambodians in RI is needed. Education should be tailored to the disease (HTN) and its control (Watson et al, 2009). There is a need for more effective treatment among the entire Asian population by the health care providers. Meeting this need will include addressing access issues as well as tailored care for a growing and ethnically diverse population of Americans. 


\section{Recommendations and Implications for Advanced Nursing Practice}

Asian peoples represent a large, multiethnic group with different cultural and religious beliefs and practices. The Cambodians are one of the subgroups of Asian peoples that are not often included or specifically identified in studies. As a result, an accurate estimate of the number of Cambodians with HTN and other conditions in the US is unknown. Likewise, the intervention methods or strategies that work best to treat HTN in Cambodians have not been tested. More research specific to Cambodian Americans is needed. One focus should relate to barriers to care in this population. There also needs to be more research on the Cambodians culture, health beliefs, and how these impact health promotion strategies. Examination of motivation to change among Cambodians is warranted. Future studies should also include larger sample sizes of Cambodians throughout the US.

In this study, more than a quarter of subjects believed that they stop taking their antihypertensive medications as soon as their blood pressure was under control and without consulting with the provider. Nurse practitioners need to explore strategies designed to reinforce the importance of taking antihypertensive medications regularly. Non-compliance with antihypertensive medications puts 
people at risk for uncontrolled blood pressure, which can lead to stroke and myocardial infarction.

It is essential that healthcare providers understand the Cambodians view of illness, and to recognize and understand cultural differences and similarities in providing care and appropriate treatment for Cambodian hypertensive patients. As currently mandated, it is essential that providers complete cultural competency training to increase awareness and understanding of varying beliefs and practices that impact health practices. Health care providers should identify ways to be actively engaged in ethnically diverse communities, including Cambodians, to provide such essential services as stroke assessment risk, blood pressure screening, and diabetes screening. As in this pilot study, engaging these peoples at different temples, where there is always a large number of Cambodians, would be an important step. Opportunities for volunteering at sites such as the Free Clinic in Providence, RI, where the minority and underserved populations such as Cambodians seek care, exist and should be encouraged. The APRs should also seek support from healthcare institutions to provide opportunities that would provide exposure to diverse populations and their care needs.

Advance practice nurses need to continue to build effective and creative strategies to develop and enhance therapeutic relationships with clients. . As supported in the literature, development of a positive client/provider relationship is key to initiating and maintaining treatment. The APRN is in a unique position to influence practice of the health care team in this regard. Language and translators 
are necessary and are very important for APRNs in the process of providing cares to minority populations.

Policy work is needed at the local and national level to reduce ethnic disparities and improve access, which could lead to improved health care outcomes. Through involvement in professional organizations, APRNs can be influential is supporting funding to help create health promotion programs targeted at meeting the needs of diverse clients, such as the Lowell Community Center in Massachusetts.

\section{References}

Barkley, T. W. \& Myers, C. M. (2008). Practice guidelines for acute care nurse practitioners. Hypertension. Barkley \& Javier (ed). 95-108. Saunders Elsevier: an imprint of Elsevier INC check if need comma with two initials

Bauchner, H., Fontanarosa, P. B., \& Golub, R. M. (2013). Updated guidelines for management of high blood pressure: Recommendations, reviews, and responsibility. Journal of the American medical association

Barnes P. M., Adams P. F., Powell-Griner, E. (2008). Health characterics of the Asian adult population: United States, 2004-2006. Advance data. 394: 1-22

Bitton. A., Zaslavsky. A. M., Ayanian., J. Z. (2010). Health risks, chronic diseases, and access to care among US Pacific Islanders. Journal of general internal medicine, 25(5): 435-440. DOI:10.1007/s11606-009-1241-0

Cambodia: Beauty and Darkness. (2004). Cambodia: facts, figures, and statistics.

Retrieved from Mekong net web site:

http://www.mekong.net/cambodia/facts.htm

Catolico, 0. (2013). Seeking life balance: The perceptions of health of Cambodian

women in Resettlement. Journal of Transcultural Nursing, 24(3), 236-245. 
Doi: $10.1177 / 1043659613481624$

Center for Disease Control \& Prevention. (2012). Vital sign: awareness and treatment of uncontrolled hypertension among adults-United States, 20032010. MMWR. 2012; 61(35): 703-709. Retrieved from Center for Disease Control and Prevention Web site: http://www.cdc.gov/mmwr

Center for Disease Control and Prevention. (2011). Factstats: Health of Asian or Pacific Island Population-United States 2011. Retrieved from Center for Disease Control and Prevention Web site: http://www.cdc.gov/nchs/fastats/asian_health.htm Center for Southeast Asian. (2013). Health status of Southeast Asians in Rhode Island \& Implications of the Affordable Care Act. Southeast Asian data \& trends analysis. Retrieved from Center for Southeast Asian web site: www.cseari.org Gillespie, C. D. \& Hurvitz, K. A. (2013). Supplement: prevalence of hypertension and controlled hypertension-United States. 2007-2010. MMWR 2013; 62 (03): 144148. Retrieved from Center for Disease Control and Prevention Web site:

http://www.cdc.gov/mmwr/preview/mmwrhtml/su6203a24.htm?s_cid=su6203a2 4_w

Eugene, V., \& Bourne, P. A. (2013). Hypertensive patients: knowledge, self-care management practices and challenges. Journal of behavior health, 2(3): 259268. DOI: $10.5455 / \mathrm{jbh} .20130217103511$

Grigg-Salto., Toff, R., Silka, L., Liang, S., Sou, L., Peou, S., \& Och, S. (2010). Long-term 
development of a "whole community" best practice model to address health disparities in the Cambodian refugee and immigrant community of Lowell, Massachusetts. American journal of public health, 100(11), 2026-2029. Doi: 10.2105/AJPH.177030

Kaiser Family Foundation. (2008). Fact sheet: Health coverage and access to care among Asian Americans, Native Hawaiians and Pacific Islanders. Retrieved from: http://kaiserfamilyfoundation.files.wordpress.com/2013/01/7745.pdf

Kinzie, J. D., Riley, C., McFarland, B., Hayes, M., Boehnlein, J., Leung, P., \& Adams, G. (2008). High prevalence rates of diabetes and hypertension among refugee psychiatric patients. The Journal of Nervous and Mental Disease, 96(2), 108-112. Doi: 10.1097/NMD.0b013

Leinginger, M. (2007). Theoretical questions and concerns: Response from the theory of culture care diversity and university perspective. Nursing Science Quarterly, 20(1), 9-15. DOI: 10.117/0894318406296784

\section{MADELEINE LEININGER'S CULTURE CARE: DIVERSITY AND UNIVERSALITY} THEORY http://nursing.jbpub.com/sitzman/ch15pdf.pdf

Martin, J. (2008). Hypertension guidelines: Revisiting the JNC 7 recommendation. Journal of Lancaster General Hospital, 3(3), 91-97. Retrieved from: http://www.jlgh.org/JLGH/media/Journal-LGH-MediaLibrary/Past\%20Issues/Volume\%203\%20-\%20Issue\%203/JLGH_V3n3_p9197.pdf

McEwen, M. \& Wills, E. M. (2011). Overview of selected middle range nursing theories. M. McEwen ( $3^{\text {rd }}$ Eds), Theoretical basis for nursing (pp. 220-247). Philadephia: Lippincott 
Minority health facts: Asians \& Pacific Islanders in Rhode Island http://www.health.ri.gov/publications/factsheets/minorityhealthfacts/AsianPacificI slanders.pdf

National Heart, Lung, and Blood Institute. (2014). What is high blood pressure?

Retrieved from the National Heart, Lung, and Blood Institute Web site:

http://www.nhlbi.nih.gov/health/health-topics/topics/hbp/

National Heart, Lung, and Blood Institute. (2012). What is high blood pressure?

National institute of health. Retrieved from:

http://www.nhlbi.nih.gov/health/health-topics/topics/hbp/

Palaniappan, L. P., Araneta, R. G., Assimes, T. L., Barrett-Connor, E. L., Carnethon,

M. R., Criqui, M. H., Fung, G. L., \& et. (2010). Call to action: Cardiovascular

disease in Asian Americans-A science advisory from the American Heart

Association. Circulation. 122:1242-1252. Doi: 10.1161/CIR.013e3181f22af4

Rhode Island health care matters; measuring the health of our community. The

Cambodian Community Health 2010 Project.

http://www .rihealthcarematters.org/modules.php?op=modload\&name=PromisePr $\underline{\text { actice } \& \text { file }=\text { promisePractice } \& \text { pid }=555}$

The Seventh Report of the Joint National Committee on Prevention, Detection,

Evaluation, and Treatment of High Blood Pressure. (2004). U.S. Department of

health and human services. Retrieved from the JNC 7 web site:

http://www.nhlbi.nih.gov/guidelines/hypertension/jnc7full.pdf

Ueshima, H., Sekikawa, A., Miura, K., Turin, T. C., Takashima, N., Kita, Y., Watanabe, et al. (2008). Cardiovascular disease and risk factors in Asia: A selected review. Circulation, 118(25), 2702-2709. Doi:10.1161/CIRCULATIONAHA.108.790048

Ursua, R., Aguilar, D., Wyatt, L., Tandon, S. D., Escondo, K., Rey, M., Trinh-Shevrin, 
C. (2008). Awareness, treatment, and control of hypertension among Filipino immigrants. Journal of general internal medicine.

Doi:10.1007/s11606-013-2629-4

U.S. Department of Commerce: United States Census Bureau. (2010).

American factfinder. Retrieved from:

http://factfinder2.census.gov/faces/nav/jsf/pages/index.xhtml\#\#\#

Watson, R. E., Karnchanasorn, R., \& Gossain, V. V. (2009). Hypertension in Asian/Pacific Island Americans. The journal of clinical hypertension. 11(3):

148-152. Doi: 10.1111/j.1751-7176.2009.00088.x

Wu, Y., Tai, E., Heng, D., Tan, C. E., Low, L. P., \& Lee, J. (2009). Risk factors associated with hypertension awareness, treatment, and control in a multi-ethnic Asian population. Journal of hypertension, 27, 190-197. Doi:10.1097/HJH.0b013e328317c8c3

Yee, B. W. K. Health and Health Care of Southeast Asian American Elders: Vietnamese, Cambodian, Hmong and Laotian Elders. Retrieved from: http://www.stanford.edu/group/ethnoger/southeastasian.html 


\section{Appendix A}
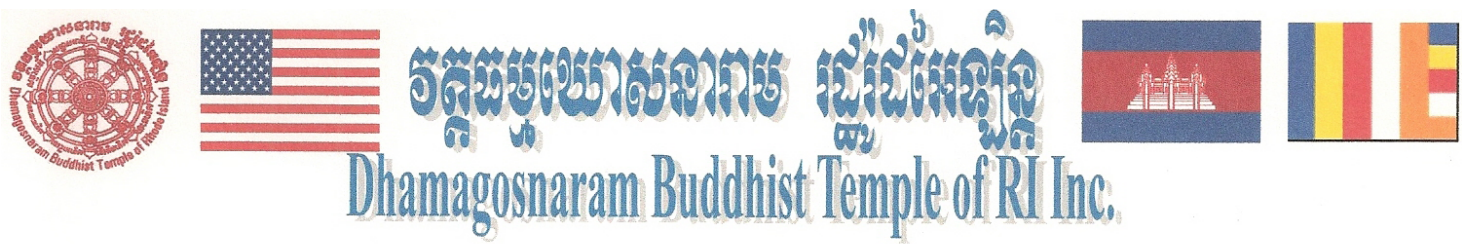

2870 Plainfield Pike,Cranston,RI 02921, Tel: (401) 942-2084

www.dhamagosmaramofri.org

To Whom It May Concern :

I'm writing to let you know that I am permitting Rathana Long to conduct a qualitative descriptive study of how Cambodians in RI manage hypertension at our temple, Wat Dhamagosnaram 2870 Plainfield Pike, Cranston, RI 02921. The study will take place in April 2014.

If you have any further question, please do not hesitate to contact me at Dhamagosnaramofri.org (401)942-2084.

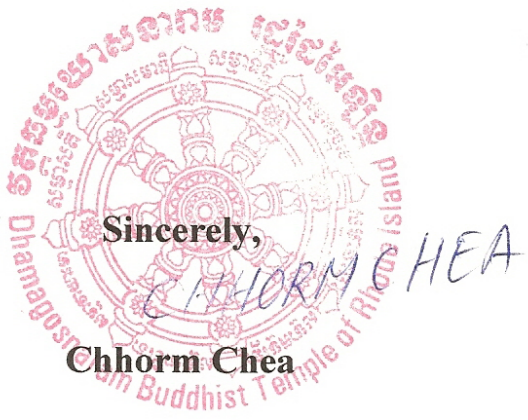




\section{Appendix B}

Rhode Island College Institutional Review
Board $\begin{array}{r}\text { Participant's Initials: } \\ \text { Approval \#: } 1314-1036 \\ \text { Expiration date: } 4 / 7 / 2015\end{array}$

\section{CONSENT DOCUMENT Rhode Island College}

Hypertension Management Among Cambodians in Rhode Island

You are being asked to participate in a research study about How Cambodians in Rhode Island manage high blood pressure (hypertension). You were selected as a possible participant because you are Cambodian and you have hypertension. Please read this form and ask any questions that you may have before deciding whether to be in the study.

Rathana Long, a nurse practitioner student at Rhode Island College, is conducting this study.

\section{Background Information}

The purpose of this research is to determine what do Cambodians in Rhode Island do to keep blood pressure under-control.

\section{Procedures}

If you choose to be a participant in this research, you will be asked to answer 15survey questions that will take approximately 10 minutes. There is no compensation but will check your blood pressure for your participation in the study.

\section{Risks of Being in the Study}

The main risk of participating in this research is that you might become alarm and anxious if your blood pressure is high when check as you turn in the survey.

\section{Benefits to You}

There are no direct benefits to you for participating in the study. 


\section{Voluntary Participation}

Your participation is completely voluntary. It is not required by anybody. You can choose not to participate in this research and it will have no effect on your health. Also, you can change your mind about participating at any time with no negative consequences.

\section{Confidentiality}

The records of this research will be kept private. In any sort of report that might be published, the researcher will not include any information that will make it possible to identify you. Research records will be kept in a secured file, and access will be limited to the researcher. If there are problems with the study, the research records may be viewed by Rhode Island College review board responsible for protecting human participants and other government agencies that protect human participants in research. All data will be kept for a minimum of three years, after which it will be destroyed.

\section{Contacts and Questions}

The researcher conducting this study is Rathana Long. You may ask any questions you have now. If you have any questions later, you may contact her at rlong_1586@ric.edu and/or her faculty advisor at cpadula@ric.edu. If you think you were treated unfairly or would like to talk to someone other than the researcher about your rights or safety as a research participant, please contact Dr. Christine Marco, Chair of the Rhode Island College Institutional Review Board at IRB@ric.edu, or by phone at 401-456-8598, or by writing to Dr. Christine Marco, Chair IRB; c/o Department of Psychology, Horace Mann Hall 311; Rhode Island College; 600 Mount Pleasant Avenue; Providence, RI 02908.

You will be given a copy of this form for your records.

\section{Statement of Consent}

I have read and understand the information above, and I agree to participate in the study "Hypertension Management Among Cambodians in Rhode Island" I understand that my participation is voluntary and can be withdrawn at any time with no negative consequences. I have received answers to the questions I asked, or I will contact the researcher with any future questions that arise. I am at least 18 years of age. 
Print Name of Participant:

Signature of Participant:

Date:

Name of Researcher Obtaining Consent: Rathana Long

Appendix C

Socio-demographic Data Questions

1. How old are you? 
18-24 years old

25-34 years old

35-44 years old

45-54 years old

55-64 years old

$65+$ years old

2. What is your gender?

Female

Male

3. What is your highest level of education?

High school graduate

2 years Associate degree

4 years Bachelor degree

Master degree

$\mathrm{PhD}$

4. Marital status

Single

Married

Common-Law

Widowed

\section{Self-care Management Questions*}

5. How long have you been diagnosed with high blood pressure?

6. How many medications are you taking for high blood pressure?

The remaining questions will be answered using the following scale:

\begin{tabular}{|c|c|c|c|c|}
\hline $\begin{array}{c}\text { (1) Strongly } \\
\text { Disagree }\end{array}$ & (2) Disagree & (3) Neutral & (4) Agree & $\begin{array}{c}\text { (5) Strongly } \\
\text { Agree }\end{array}$ \\
\hline
\end{tabular}




\begin{tabular}{|l|l|}
\hline 7. I will eat more fruits and vegetables & \\
\hline 8. I will put less salt in my food & \\
\hline 9. I make every attempt to avoid smoking cigarettes & \\
\hline 10. I make every attempt to avoid drinking alcohol & \\
\hline 11. I take my medication daily as prescribed by the doctor & \\
\hline 12. As a person with high blood pressure, I will exercise regularly & \\
\hline 13. As soon as the blood pressure is low, I can stop taking the medication & \\
\hline $\begin{array}{l}\text { 14. It is OK for the persons with high blood pressure to take Khmer herbal } \\
\text { medications to lower their blood pressure }\end{array}$ & \\
\hline
\end{tabular}

*Eugene, V., \& Bourne, P., A. (2013). Hypertensive patients: knowledge, self-care management practices and challenges. Journal of Behavior Health, 2(3): 259-268.

DOI: $10.5455 /$ jbh.20130217103511

\section{Appendix D}

\section{Debriefing}

Thank you for participating in the study: Hypertension Management Among Cambodians in Rhode Island. The information you've given will help us to learn about the different treatments people use for hypertension. Always remember to consult with your doctor or health care provider before stopping or starting treatments for your blood pressure. Please DO NOT stop taking your blood pressure medications without first consulting with your doctor or health care provider. Also, Please DO NOT take the Khmer herbal medications without first consulting with your doctor or health care provider. 
Rhode Island College Institutional Review Board

Approval \#: 1314-1036

Expiration date: $4 / 7 / 2015$

Document version: 4.2014 Page 1 of 1 